\title{
Accessibility versus air pollution: a geography of externalities in the Brussels agglomeration
}

Nicola da Schio

Kobe Boussauw ${ }^{i}$

Joren Sansen ${ }^{\mathrm{i}}$

i Vrije Universiteit Brussel, Cosmopolis Centre for Urban Research VUB - Pleinlaan 2, 1050 Brussels, Belgium

To be cited as:

da Schio, N., Boussauw K., Sansen J. (2018), Accessibility versus air pollution: a geography of externalities in the Brussels agglomeration, in Cities

https://doi.org/10.1016/i.cities.2018.08.006

This paper proposes a novel approach to investigate the geography of accessibility and air pollution and tests it on the case of the Brussels Capital Region. First, we find a strong positive correlation between accessibility and air pollution, highlighting a trade-off that exists between two emblematic but antithetical externalities of agglomerations. Next, we focus on the outliers that escape this trade-off and we develop a methodology to combine their respective levels of accessibility and air pollution into a 'desirability' indicator. Finally, we analyse the distribution of the most and the least desirable neighbourhoods across the city: while we observe flagrant patterns of inequality, these do not reflect the socio-economic structure of the region, in apparent contrast with the literature on transport justice and environmental justice. The results show how positive and negative socio-ecological externalities can be two sides of the same agglomeration coin. The methodology proves to be relevant to further comparative research and policy making concerned with promoting a balanced progress of social, economic and environmental priorities.

Keywords: air pollution; accessibility; agglomeration effects; spatial justice 


\section{Introduction}

The physical proximity and the functional integration of people, firms and infrastructure that make up cities results in a range of-sometimes antithetical-socio-ecological externalities. These are referred to as agglomeration economies and diseconomies, and are positioned under the umbrella concepts of agglomeration benefits and congestion costs. But how are they related to each other? How are they distributed across the city and among people? How is it possible to analyse them simultaneously? To respond to these questions, we focus on two emblematic externalities of agglomeration, namely accessibility and air pollution, while taking the Brussels Capital Region (BCR), Belgium, as a case study.

The combined analysis of correlated but off-setting externalities of agglomeration is relevant to understand long-term equilibrium outcomes of urban areas. Exploring in particular the relationship between air pollution and accessibility may provide arguments to support a more holistic approach to urban governance; it would contribute to bridge gaps between public health and spatial planning priorities (Verbeek \& Boelens, 2016), or provide important insights to the sustainable mobility discussion, which places emphasis on the need to combine the socioeconomic gains deriving from accessibility with urban liveability and environmental performance (Berger, Feindt, Holden, \& Rubik, 2014).

In this context, the BCR is an especially illustrative case study, inasmuch as its mobility agenda was historically dominated by divergent visions of the city, prioritising respectively its accessibility or its liveability (Genard, Berger, \& Vanhellemont, 2017). According to the former vision, the priority is to be given to accessibility, possibly at the expenses of air quality, for instance through actively developing a more rapid and cost-effective metropolitan road network. For the latter, conversely, it is about setting the conditions for a liveable, non polluted urban core, possibly at the expenses of regional accessibility (Vanhellemont, 2016).

The objective of this article is to present a novel methodological approach to investigate the correlation between accessibility and air pollution, their relative distributions, and to test it on the Brussels Capital Region. In the remainder of the article we illustrate how these themes were researched within different bodies of literature; while agglomeration studies explore the presence of and the relation between positive and negative externalities, spatial justice research looks at their distribution in relation to socio-economic dynamics. Against this backdrop, we hypothesise a positive correlation between the two attributes. We also hypothesise that the relative distribution of accessibility and pollution reflects regional socio-economic stratification, whereby disadvantaged groups are penalised by high costs (air pollution) and low benefits (accessibility). Afterward, we present the data on accessibility and air pollution, as well as the methodology which we have developed to combine both sets of data into 'agglomeration' and 'desirability' indicators. Our analysis, which only confirms the first hypothesis, has policy implications within a sustainable mobility perspective. These implications are presented in the conclusion together with an indication of venues of further research. 


\section{Context and bibliographic review}

\section{Costs and benefits of agglomeration: the case of accessibility versus air pollution}

The positive externalities of urban agglomerations have long been recognised. Alfred Marshall's seminal work (1890; in Schleicher, 2009) already suggested that reduced transport costs, insurance and specialization gains from large labour and consumption markets, and information spill-overs would result in increasing returns. In contemporary urban theory, Glaeser (1998) illustrates how urban density results in reduced transport costs for goods, people and information, acknowledging that the manifestations of these benefits have shifted in history (e.g. from industrialisation to the service economy). A similar and widely quoted taxonomy of the relational assets that agglomerations provide refers to mechanisms of sharing (e.g. of large facilities and infrastructures), matching (e.g. of people and sought for skills), and learning (e.g. about innovative ways of working) (Duranton \& Puga, 2004).

In our research, we focus on geographic accessibility. This has been defined in many different ways. In one of the first definitions it was simply defined as 'the potential of opportunities for interaction' (Hansen, 1959), while others define it more specifically as 'the ability of the people to reach and engage in opportunities and activities' (Bisht, Mishra, \& Fuloria, 2009, p. 167) or as 'the extent to which land-use and transport systems enable (groups of) individuals to reach activities or destinations by means of a (combination of) transport mode(s)' (Geurs \& van Wee, 2004, p. 128). In the context of our research, we ought to emphasise how the notion of accessibility includes both a land-use dimension (where are people and activities, proxied by population density), and a transport dimension (how to connect them, proxied by travel time). A smooth interplay of these two dimensions within a city's specific configuration is a necessary ingredient to ensure that the proximity of people and firms translates into fruitful interaction, and that the benefits of agglomeration can be maximized. Overall, geographic accessibility is an asset for a city and its residents because it implies that opportunities of interaction are high, while resources spent on travel are low.

While they collectively contribute to the prosperity of a city, however, people and firms take up space and time. "It is not simply a case of "the more the merrier": each additional participant can add value only by burning up scarce inputs' (Fennell, 2015, p. 1374 emphasis in the original). Negative externalities of agglomeration range from competition for scarce resources (i.e. the agglomeration benefits themselves and the limited space to enjoy them), to the residents' responses to such competitive environment, which can impede the production of agglomeration benefits in the first place (Fennell, 2015). These negative externalities can take the form of overcrowding and congestion, increasing housing costs, segregation, crime, the degradation of the ecosystem and the saturation of its capacity to absorb gaseous, liquid and solid refuses of the city, as in the case of air pollution.

Air pollution is '...the presence of contaminant or pollutant substances in the air that do not disperse properly and that interfere with human health or welfare, or produce other harmful environmental effects' (UNEP, 2016). In the agglomeration frame, air pollution is a particularly emblematic urban congestion problem, given that cities concentrate its sources, such as transport, industries and space heating, along with the people affected by it. Given the magnitude of the problem, the question today is not 'if' air in cities is polluted, but 'how much' it is polluted and how dramatic are its impacts. In the European Union, long term exposure to 
$\mathrm{PM}_{2.5}, \mathrm{NO}_{2}$ and $\mathrm{O}_{3}$ concentrations was estimated to be responsible for a total of almost half a million premature deaths in 2014, and of a wide range of adverse impacts on human health. In addition, air pollution has significant economic impacts, (by increasing healthcare costs and leading to working days loss) negative impact on ecosystems, agriculture and the built environment (European Environment Agency, 2017). Despite a certain improvement over the last decades, air pollution is still a key health and environmental issue in the BCR too, with transport related $\mathrm{NO}_{2}$ and black carbon emissions being the main culprit (see Da Schio, de Geus, \& Bouland, 2017 for an overview of the air pollution related issues in the BCR).

Positive and negative externalities, we contend, are two sides of the agglomeration coin; if the forces of agglomeration economies make cities grow and thrive, various forms of congestion and overcrowding potentially hinder prosperity and people's well-being. Indeed, the very future of cities depends on figuring out a balance between benefits and costs, maintaining and enhancing the former while mitigating and reducing the latter (Glaeser, 1998; see also Brinkman, 2016 for an analysis of the tradeoff between agglomeration costs and benefits in the context of transport policy).

\section{Spatial inequality of accessibility and pollution}

The externalities of agglomeration are virtually nowhere distributed equally across space; development never takes place uniformly and the friction of distance unavoidably produces and reproduces spatial unevenness (Soja, 2010). While 'inequality' is not inherently undesirable or unfair, it becomes 'injustice' when it reflects structurally imbalanced power relations. This concept, as opposed to inequality, implies an eminently normative claim about the distribution of given advantages and disadvantages, and about the processes leading to it (Walker, 2012). The concept of spatial justice does not indicate simply another form of justice: it rather refers to the fact that justice is always inherently spatial, as much as space is inherently socialised and socially constructed. As our study simultaneously considers the distribution of accessibility and air pollution, we build on and combine the insights of the literature on two different manifestations of spatial justice and inequality, namely on justice and inequality related to transport and to the environment.

The literature on transport justice shows how spatial inequality is produced and reproduced by the configuration of transport systems, including the locations they serve, the business models they adopt, and whether they provide for people with different abilities (Martens, 2016). In this context, the notion of 'transport disadvantage' refers to the unequal distribution of the benefits of a transport system, including public transport and car accessibility, and 'transport-related social exclusion' to the potentially unjust conditions under which those who experience transport disadvantage are also socially excluded (Lucas, 2004, 2012). A review of transport surveys in different countries by Lucas (2012) found that those who experience transport disadvantage are usually the poorest and most socially disadvantaged within society, while the reverse direction (i.e. the extent to which limited mobility and access to services reduces social capital and leads to social exclusion) seems to be statistically less clear.

The notion of environmental (in)justice and inequality, in turn, refers to the (spatial) distribution of environmental assets and vulnerabilities, and to its intertwining with social differences (Walker, 2012). The empirical research investigating the uneven distribution of pollution among areas, individuals and social groups shows mixed results. Research dealing with North American 
cases consistently shows that areas populated by communities with a lower socio-economic status tend to experience higher concentrations of air pollutants (Hajat, Hsia, \& O'Neill, 2015). Studies conducted in European cities, conversely, reveal a more ambiguous picture. A 2010 review of European articles on social inequality and health risks related to ambient air quality, for instance, showed that in some cases, poorer people were found to be more exposed to air pollution, whereas the reverse was observed in other cases (Deguen \& Zmirou-Navier, 2010). Similarly, a 2017 study involving almost 6000 participants in 16 European cities also showed weak and inconsistent relations between individual socio-economic position and exposure to air pollution (i.e. $\mathrm{NO}_{2}$ ) across the studied cities (Temam et al., 2017).

Similar and related to the environmental justice and transport justice literature, but rooted in a different research community, are those studies that assess how environmental and accessibility indicators are correlated with property values. Actual and perceived air pollution, on the one hand, is shown to have a negative impact on housing demand, and consequently on values in urban real estate markets, as shown by various econometric studies (Luc Anselin \& LozanoGracia, 2008; Harrison \& Rubinfeld, 1978; Nelson, 1978; Ridker \& Henning, 1967). Another, more extensive line of inquiry analysed the assumed impact of accessibility on property values. The base hypothesis that better accessibility translates into higher real estate values was confirmed in a wide variety of contexts, including research by Srour et al. (2002), which should not be too surprising considering the direct impact of location-based accessibility on the general ability to participate in all kinds of social activities. By reflecting the distribution of air pollution and accessibility, property values act as an intermediate variable and potentially reproduce patterns of spatial inequality (i.e. environmental and transport-related); neighbourhoods combining high levels of pollution and low levels of accessibility would be characterised by lower values, thereby attracting the poorest segments of the population, whereas neighbourhoods combining better scores of the two attributes would only be affordable to more well-off residents.

\section{Research hypotheses}

In our study, we explore the correlation between accessibility and air pollution as an emblematic case of socio-ecological trade-off between benefits and costs of agglomerations. If, generally speaking, the level of geographic accessibility is both due to the density of population and activities, and to the relative performance of the road and transport network, the former element is predominant in compact cities. In this context, it is not imaginary that neighbourhoods that show the highest levels of accessibility are also characterised by higher air pollution levels. While greater density of households and of interactions contributes to higher accessibility scores, it also implies greater concentration of emissions sources, resulting in higher concentrations of pollutants in the atmosphere.

The complex relationship between these two types of externalities is illustrated respectively by the literature on transport justice and on environmental justice, which emphasise the association between transport disadvantage and environmental vulnerability as a result of socio-economic deprivation, with real estate value acting as intermediate variable. Compact and dense cities, however, seem to be characterised by an element of proximity and amalgamation, making the assumptions on the distribution of resources, vulnerabilities, and their relation with socioeconomic indicators not immediately applicable. We want to investigate this reasoning and we 
hypothesise that the level of air pollution in a given neighbourhood is positively correlated with its geographical accessibility (\#1 - agglomeration hypothesis).

In addition, we want to look at the distribution of neighbourhoods that deviate from this hypothetical correlation and at the links with the socio-economic stratification of the BCR. In this context, we propose the concept of 'desirability' as a property of neighbourhoods that combines high levels of accessibility with low levels of pollution. We use the term desirable in a limitative way, using an indicator which only combines accessibility and pollution and excludes the range of other costs and benefits of agglomerations. We also use it in a normative way, as we assume that low levels of pollution and high levels of accessibility are socio-ecological goods that describe desirable conditions for every person and place in the same way. In fact, certain groups, such as children and elderly people, are more vulnerable to air pollution than others. Similarly, car and public transport accessibility are likely to be valued in different ways by different people depending, for instance, on how they 'experience' the city, on whether and how they commute, or on car ownership and actual car use.

Building on literature on transport justice and on environmental justice, we hypothesise that unequal distribution of 'desirability' across the BCR neighbourhoods reflects local socioeconomic status (\#2 - spatial justice hypothesis). We limit our analysis to considerations regarding the distributive notion of inequality (e.g. as opposed to its procedural aspects), where the main stake is the distribution of resources and vulnerabilities, and its embeddedness in the sociospatial dialectic. Also, we choose to focus on the different levels of exposure to pollution and of accessibility, leaving questions related to need, vulnerability, merit and responsibility out of the scope of our paper.

\section{Data}

\section{Accessibility}

In this study, accessibility is conceptualized as interaction potential. More specifically, the accessibility of a given neighbourhood relative to other neighbourhoods depends on (a) travel time between origin and destination and on (b) the amount of 'opportunities' to interact with. Origins are defined as places of residence and destinations are broadly defined as 'opportunities', i.e. all possible activities people can engage in during the course of a day. To capture the complex and subjective range of these 'opportunities', this study uses population as a proxy for the available amount of opportunities, adopting the assumption that the concentration of people is the necessary precondition for any development of amenities. As past zoning practices and path dependent processes resulted in a heterogeneous, sometimes segregated urban landscape, the one-on-one relationship between people and opportunities does not always apply on a microlevel. Therefore, a possible underestimation of accessibility values next to clusters of job opportunities and services (e.g. shopping districts and North or European Quarter) is expected. Finally, travel time between origin and destination acts as a force of friction and hinders the potential to interact. As travel time largely depends on mode of transport, we produce separate maps using car based accessibility (data from TOMTOM, 2013) and public transport-based 
accessibility (data from Lebrun (forthcoming), see also Lebrun (2016) for a detailed description of the calculation method). Census wards will be used as a basic unit of analysis ${ }^{1}$.

Translated to a workable definition, the accessibility (ACC) of a census ward (i) is defined as the sum of the number of residents (POP) of each census ward in the BCR (j) divided by the required travel time $\left(D_{i j}\right)$ to this census ward.

$$
A C C_{i}=\sum_{j=1}^{m} \frac{P O P_{j}}{D_{i j}}
$$

In the case of car accessibility, the distance measure $\left(D_{i j}\right)$ is derived from the TOMTOM-2013 database using the shortest path (Dijkstra algorithm) between the centroid of the census ward (i) and the centroids of all other census wards in the BCR (j). As a result, an unweighted average of the real-time traffic situation during a typical working day in the year 2013 is incorporated in $D_{i j}$.

In the case of public transport accessibility, median travel times at the morning peak hour are used, all four transport operators offering services in Brussels included (SNCB, STIB, De Lijn and TEC). As travel times by public transport can fluctuate heavily depending on the starting time, medians are used to address fluctuations in frequency and more accurately reflect actual use.

\section{Air pollution}

With regard to air pollution, we base our analysis on the 2015 data of the Atmosys annual air quality maps (Atmosys.eu, 2015), produced by the Flemish Institute for Technological Research (VITO) and the Belgian Interregional Environment Agency (IRCELINE). These maps provide historical data records of air pollution for the entire Belgian territory with data on average exposure of different air pollutants, i.e. $\mathrm{PM}_{10}, \mathrm{PM}_{2.5}, \mathrm{O}_{3}$, and $\mathrm{NO}_{2}$. They result from a combination of two methods, namely the RIO and the IFDM models. The RIO model produces hourly concentration maps on a four square kilometre grid. It uses the measurements from the regional telemetric network and interpolates them while taking into account information about land use (Janssen, Dumont, Fierens, \& Mensink, 2008). The IFDM-model is a bi-Gaussian plume model, designed to simulate non-reactive pollutant dispersion at a local scale. It estimates the local concentration of pollutants based on emissions and meteorological data (Lefebvre \& Vranckx, 2013). The combination of the two models allows for the coupling of their respective strengths and for the estimation of air quality at a detailed spatial resolution. At the time of writing, the Atmosys air quality maps provide the most detailed and reliable information about air pollution in the BCR. Its main weakness is related to the fact that the RIO-IFDM is an 'open-street' twodimensional technique, which means that effects of street canyons and topography are not accounted for and that no information is available on traffic emissions in small and very 'low traffic' roads, for which data is estimated (Atmosys.eu, 2015). The modelled values were aggregated to census wards by calculating the spatial average across the ward and attributing it

1 The census ward, also called 'statistical sector', is the calibrated geographical format used in Belgium to collect data at the neighbourhood level. The BCR comprises 720 census wards. 
to the ward's centroid. While the use of a wider spatial aggregation might blur the differences between places within the same census ward, it also reduces the aforementioned uncertainties, which are more pronounced at the microscale. In addition, this choice makes it possible to combine the air pollution and accessibility datasets in a meaningful way.

For our analysis, we only use data on nitrogen dioxide $\left(\mathrm{NO}_{2}\right)$. The direct impact on health of long term (moderate) exposure to this pollutant is difficult to isolate in epidemiological research. At the same time, $\mathrm{NO}_{2}$ is often used as a proxy for health-adverse pollution related to transport, as $\mathrm{NO}_{2}$ emissions are strongly correlated with the emission of a mixture of other pollutants that also originate from road transport, the health impacts of which have been recognised. $\mathrm{NO}_{2}$ is also among the most problematic pollutants in the BCR, as different monitoring stations record annual mean concentrations beyond the limit value authorised by the EU legislation (European Parliament \& European Council, 2008; Bruxelles Environnement, 2015, 2016a). On average, 47\% of $\mathrm{NO}_{2}$ emissions are linked to road transport, $13 \%$ to urban background air pollution, and $40 \%$ to sources external to the region (Bruxelles Environnement, 2016b).

\section{Property values}

We use property values as an intermediate socio-economic indicator between a neighbourhood's accessibility, air pollution levels, and the socio-economic status of the residents. In particular, we use the average sales price of two official categories of housing in the analysis, namely 'common' houses (row houses) and apartments. This data was made available by the Cadastre (national property registry) for sales of both types of homes in 2010 and 2011. These data are only representative to a certain extent, since some census wards only include a very small number of transactions, and furthermore no information is disclosed about the characteristics of the property sold.

\section{Applied geographical scale level}

We choose to conduct our analysis at the scale of the BCR for different reasons.

As the accessibility analysis focuses on potential interaction between people from an urban agglomeration perspective, population density and current travel behaviour are the main determinants in the delineation of our research area. With respect to population density, falling levels are already present in the fringes of the administrative borders of the BCR (Institut Bruxellois de Statistique et d'Analyse, 2015). Historically acting as an urban growth boundary (Boussauw, Allaert, \& Witlox, 2013), this relatively steep decline in population density lowers possible border effects on the outer parts of the BCR and would result in levels of accessibility only slightly lower than expected.

With respect to travel behaviour, studies show that BCR residents are more likely to circulate only within the regional borders. Outward mobility, although slightly increasing (Barette, 2011), still plays only a minor part in overall travel movements. Lastly, extending our research area beyond the densely populated area of the BCR would increase variation in pollution and accessibility scores with the risk of masking interesting details on the local level.

The main objective of this article is to introduce a novel methodology to simultaneously analyse accessibility and air pollution and to test it on the territory of the BCR. In this context, the results need to be approached with a certain caution: if the BCR would have been a fully isolated urban area, the methodology would not suffer from any border distortion. Conversely, the region's agglomeration dynamics are not only explained by internal dynamics but are also partially 
affected by its embeddedness within the broader metro area and country. Overall, any geographical research imposes a choice of scale: While we propose the BCR as a case study, further research could build upon the tool we developed for this study and apply it for an analysis of the Brussels metropolitan area or as a tool of comparison with other urban or regional agglomerations.

\section{Methods}

Our methodological approach makes a complementary use of exploratory maps and correlation matrices and visualizations. The combination of both methods allows us to draw agglomeration and desirability maps. Through these maps and graphs, we analyse the geographic distribution of the different types of neighbourhoods and explore the possible relationships between socioeconomic characteristics and desirability.

We first develop a number of maps based on absolute levels of air pollution and accessibility to provide insight into the characteristics of different neighbourhoods in the BCR at the census ward level ${ }^{2}$. To identify both geographical proximity and distribution of air pollution and accessibility, we conduct a spatial autocorrelation analysis. This is particularly useful to show if the variables under scrutiny present similar or different patterns in neighbouring locations and are therefore subject to spatial dependencies (Caschili, De Montis, \& Trogu, 2015). Figures 1, 2 and 3 are based on LISA ${ }^{3}$ cluster visualisation (Anselin, 1995) and show clusters of census wards with above average values surrounded by above average values, and those showing below average values surrounded by below average values, indicating the clusters of census wards with a statistically significant deviation from the average.

We look then at the correlation between the variables. We produce an exploratory Pearson's correlation matrix including the variables indicated above, namely public transport accessibility, car accessibility, annual mean concentration of $\mathrm{NO}_{2}$, and sales price of row houses and apartments. Statistically significant relationships are then tested for robustness by applying 'spatial lag' and 'spatial error' models that account for the possible effects of spatial autocorrelation. Spatial autocorrelation is the correlation between values of a variable resulting from the proximity of the locations where these values are measured. To control for this effect, we adopt a 'spatial regression' technique (Luc Anselin \& Bera, 1998). This method starts from a significance test for spatial autocorrelation based on the calculation of Moran's I. If the Moran's I test is significant (which is usually the case), the occurring kind of spatial dependence ('spatial lag' or 'spatial error') should be detected. Depending on the occurrence of spatial lag or spatial error, a regression model is selected that reduces the influence of these phenomena. Each of these calculations provide, inter alia, a regression coefficient, a measure of significance and a pseudo-coefficient of determination (pseudo-R2).

To analyse the relative distribution of accessibility and pollution, we develop two indicators: the agglomeration indicator and the desirability indicator. The first allows us to rank census wards combining analogous levels of accessibility and pollution (high-high or low-low), the second to rank census wards that either present high levels of access and low levels of pollution or vice-

\footnotetext{
${ }^{2}$ Not all exploratory maps developed are included in this paper.

${ }^{3}$ Local Indicators of Spatial Association
} 
versa. These indicators are obtained by normalizing the regression residuals (into z-scores) and multiplying these with the normalized (again into z-scores) accessibility values. Based on these indicators, we develop two combined agglomeration and desirability maps. These represent the geographical distribution of census wards, respectively characterised by (i) high levels of accessibility and pollution, (ii) low levels of both characteristics, (iii) above average accessibility, with below-expectation levels of pollution, and (iv) below average accessibility and aboveexpectation levels of pollution. Since the difference between the census wards that are close to the axes of average accessibility or expected exposure in figures 4 and 5 is often very small, assigning these wards to 'grey', 'green' or 'red' sectors might be rather artificial. This is why we only assigned colours to census wards if their level of access is at least 0.25 standard deviations above or below the average, and if simultaneously their experienced level of pollution is removed at least 0.25 standard deviations from the regression line.

\section{Analysis \& results}

\section{BCR geography of accessibility and pollution}

Figures 1, 2 and 3 present local clusters of spatial autocorrelation with respect to car accessibility, public transport accessibility and $\mathrm{NO}_{2}$ annual mean concentration respectively. Red means that locally high values occur within a cluster of high values, under the condition that spatial autocorrelation is statistically significant ( $p$-value $<0.05$ ). Blue indicates the presence of low values within a cluster of low values. For the neighbourhoods in grey, spatial autocorrelation is not statistically significant.

Figures 1 and 2 show that the entire central area of the BCR consists of a cluster of census wards with a good accessibility score. This area consists of the city centre (also known as 'the pentagon', for the shape of the historical city wall) and the so-called first belt, including a number of more affluent neighbourhoods south-east of the centre and the European district, and the western and southern popular neighbourhoods. The clusters of census wards with low accessibility scores are located in the periphery of the region, consisting of low-density neighbourhoods (including the Sonian forest and a number of industrial sites). As mentioned above, some border effects may be present here.

Figure 3 shows a pattern of $\mathrm{NO}_{2}$ annual mean concentration that is rather concentric, although distorted by the presence of a number of important traffic arterials, which include the supply routes to the E40 and E19 national motorways and the inner ring road. The clusters of census wards with low pollution levels are mainly located in the wooded areas in the southeast of the region. Note that there is no border effect here, since the Atmosys model was developed for the whole of Belgium. 


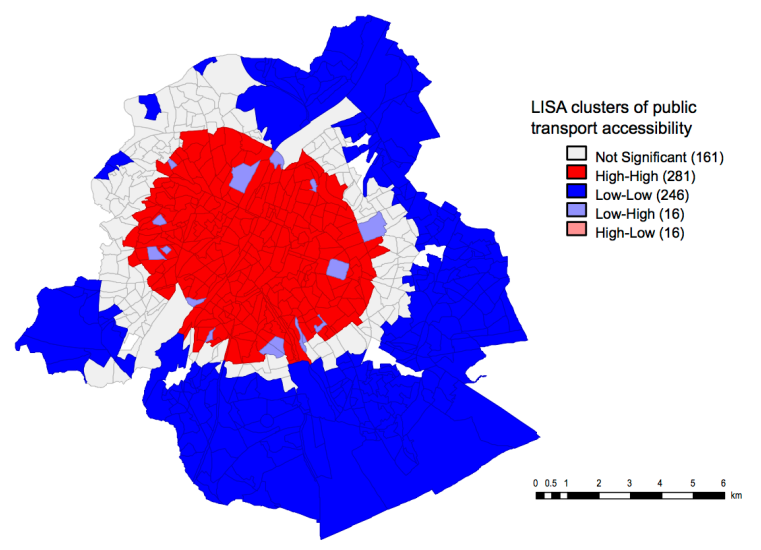

Figure 1 - LISA cluster: public transport accessibility

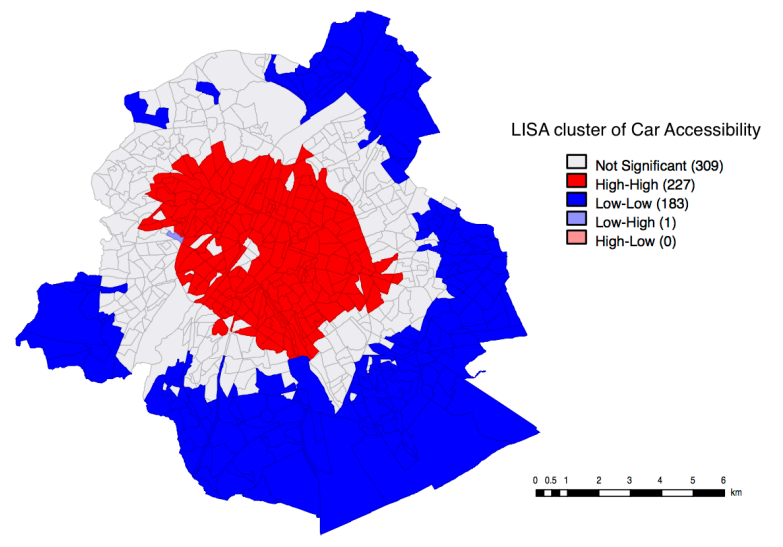

Figure 2 - LISA cluster: car accessibility

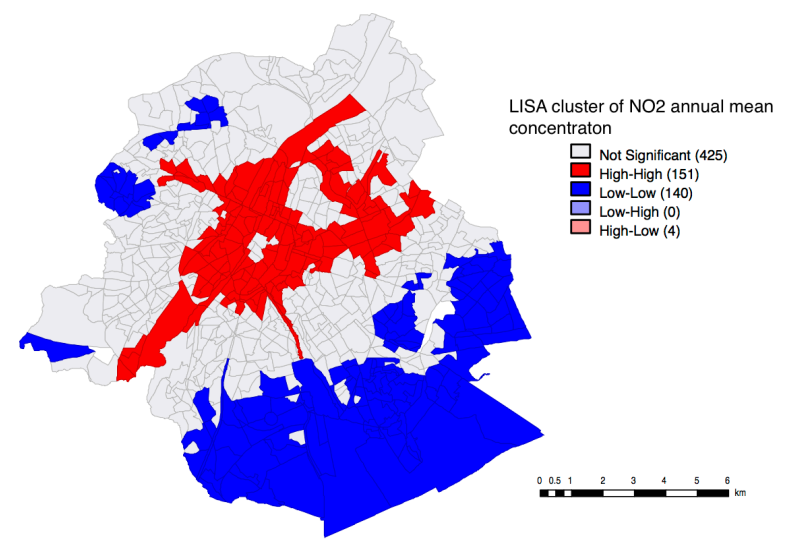

Figure 3 - LISA cluster: $\mathrm{NO}_{2}$ annual mean concentration

\section{Agglomeration externalities: trade-offs and correlations}

Table 1 shows a Pearson's correlation matrix including all the variables listed above.

We observe that car accessibility and public transport accessibility are highly correlated, indicating that, to a large extent, the road and the public transport network serve the city in a similar fashion. Both accessibility measures are highly correlated with pollution levels, which 
confirms our first hypothesis. We note, however, that the correlation with public transport is slightly weaker.

There is no unambiguous correlation between property values and accessibility, on one hand, nor between property values and pollutions levels, on the other, as opposed to part of the literature (Srour, Kockelman, \& Dunn, 2002; Luc Anselin \& Lozano-Gracia, 2008; Harrison \& Rubinfeld, 1978; Nelson, 1978; Ridker \& Henning, 1967). To a certain extent, this confirms that the postulates found within the transport and environment justice literature, suggesting that the distribution of accessibility and air pollution reflects socio-economic conditions, cannot be directly applied to the case of the BCR.

\begin{tabular}{|c|c|c|c|c|c|c|}
\hline & & 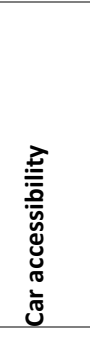 & 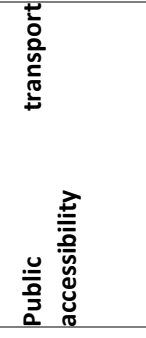 & 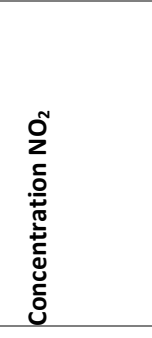 & 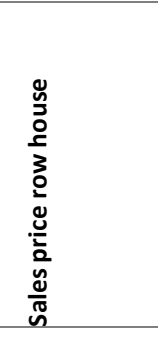 & 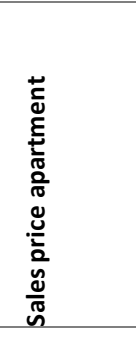 \\
\hline \multirow[t]{2}{*}{ Car accessibility } & $\mathrm{R}^{2}$ & 1.000 & $0.722 * *(+)$ & $0.454^{* *}(+)$ & $0.012 *(+)$ & $0.015^{* *}(-)$ \\
\hline & $\mathrm{p}$ & - & 0.000 & 0.000 & 0.011 & 0.003 \\
\hline \multirow[t]{2}{*}{ Public transport accessibility } & $\mathrm{R}^{2}$ & & 1.000 & $0.433^{* *}(+)$ & $0.029 * *(+)$ & $0.000(-)$ \\
\hline & $\mathrm{p}$ & & - & 0.000 & 0.000 & 0.773 \\
\hline \multirow[t]{2}{*}{ Concentration $\mathrm{NO}_{2}$} & $\mathrm{R}^{2}$ & & & 1.000 & $0.008 *(+)$ & $0.015 * *(-)$ \\
\hline & $\mathrm{p}$ & & & - & 0.037 & 0.003 \\
\hline \multirow[t]{2}{*}{ Sales price row house } & $\mathrm{R}^{2}$ & & & & 1.000 & $0.009 *(+)$ \\
\hline & $\mathrm{p}$ & & & & - & 0.036 \\
\hline \multirow[t]{2}{*}{ Sales price apartment } & $\mathrm{R}^{2}$ & & & & & 1.000 \\
\hline & $\mathrm{p}$ & & & & & - \\
\hline \multicolumn{7}{|c|}{$\begin{array}{l}p \text {-values and signs related to the regression coefficient of the independent variable } \\
\text { (for comparability, } R^{2} \text { is reported instead of } r \text { ) }\end{array}$} \\
\hline
\end{tabular}

\section{Table 1 - Pearson's correlation matrix}

Since we suspect that spatial autocorrelation is in play, we perform a Moran's I test, which shows statistically significant for all combinations. To control for spatial autocorrelation effects, we also perform 'spatial lag' (SL) and 'spatial error' (SE) regressions based on a 'rook' weights matrix. The results prove to be robust; the correlations remain significant, and R-squared's for all associations between accessibility metrics and $\mathrm{NO}_{2}$ levels remain high (Table 2 ). 


\begin{tabular}{|c|c|c|c|c|c|c|}
\hline IND\DEP & & 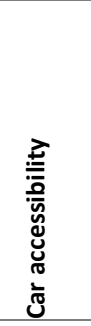 & 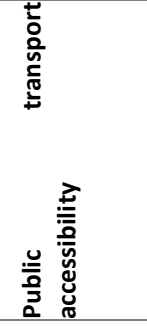 & 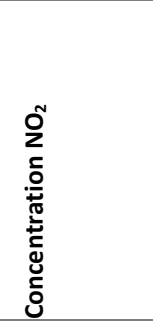 & 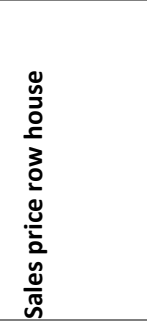 & 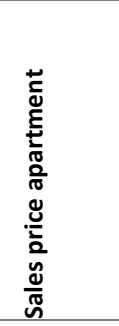 \\
\hline \multirow[t]{4}{*}{ Car accessibility } & $\mathrm{R}^{2} \mathrm{SL}$ & 1.000 & $0.799 * *(+)$ & $0.813^{* *}(+)$ & $0.284(+)$ & $0.019 *(-)$ \\
\hline & $\mathrm{p}_{\mathrm{SL}}$ & - & 0.000 & 0.000 & 0.127 & 0.021 \\
\hline & $\mathrm{R}_{\mathrm{SE}}^{2}$ & 1.000 & $0.800 * *(+)$ & $0.817 * *(+)$ & $0.283(+)$ & $0.019 *(-)$ \\
\hline & $\mathrm{p}_{\mathrm{SE}}$ & - & 0.000 & 0.000 & 0.172 & 0.019 \\
\hline \multirow[t]{4}{*}{ Public transport accessibility } & $\mathrm{R}^{2} \mathrm{SL}$ & & 1.000 & $0.792 * *(+)$ & $0.786 * *(+)$ & $0.777(+)$ \\
\hline & $\mathrm{p}_{\mathrm{SL}}$ & & - & 0.000 & 0.000 & 0.161 \\
\hline & $\mathrm{R}_{\mathrm{SE}}^{2}$ & & 1.000 & $0.787^{* *}(+)$ & $0.785 * *(+)$ & $0.778(+)$ \\
\hline & $\mathrm{p}_{\mathrm{SE}}$ & & - & 0.000 & 0.000 & 0.136 \\
\hline \multirow[t]{4}{*}{ Concentration $\mathrm{NO}_{2}$} & $\mathrm{R}^{2} \mathrm{SL}$ & & & 1.000 & $0.284(+)$ & $0.015(-)$ \\
\hline & $\mathrm{p}_{\mathrm{SL}}$ & & & - & 0.120 & 0.053 \\
\hline & $\mathrm{R}_{\mathrm{SE}}^{2}$ & & & 1.000 & $0.284(+)$ & $0.014(-)$ \\
\hline & $\mathrm{p}_{\mathrm{SE}}$ & & & - & 0.141 & 0.060 \\
\hline \multirow[t]{4}{*}{ sales price row house } & $\mathrm{R}^{2} \mathrm{SL}$ & & & & 1.000 & $0.015(+)$ \\
\hline & psL & & & & - & 0.054 \\
\hline & $\mathrm{R}^{2} \mathrm{SL}$ & & & & 1.000 & $0.014(+)$ \\
\hline & psL & & & & - & 0.065 \\
\hline \multirow[t]{4}{*}{ sales price apartment } & $\mathrm{R}^{2} \mathrm{SL}$ & & & & & 1.000 \\
\hline & $\mathrm{p}$ & & & & & - \\
\hline & $\mathrm{R}_{\mathrm{SE}}^{2}$ & & & & & 1.000 \\
\hline & PSE & & & & & - \\
\hline \multicolumn{7}{|c|}{${ }^{* *}$ significant at the 0.01 level (2-tailed) * at the 0.05 level } \\
\hline
\end{tabular}

Table 2 - Spatial lag and spatial error regression matrix

Figures 4 and 5 present a scatterplot of the correlation between the $\mathrm{NO}_{2}$ annual mean concentration and levels of accessibility at the level of the census ward (Pearson's correlation, as per Table 1). We identify four regions in the graph based on the mean level of accessibility and the regression line. The four regions correspond to four ideal-typical neighbourhoods. In the topright and the bottom-left corners (in grey) we find the ones that correspond to the 'norm', i.e. those which combine high levels of accessibility and high levels of pollution, or low levels of accessibility and low levels of pollution respectively. In the top-left corner (in red) we find the ones that deviate from the norm, possibly representing the worse conditions of lower-thanaverage accessibility and higher-than-expected levels of pollution. In the bottom-right corner (in green), finally, we find the presumably best conditions; in these census wards, accessibility levels are relatively high and pollution levels are lower than expected. These neighbourhoods are potentially the most desirable from a residential choice perspective and examples of urban structures from which we can learn. 


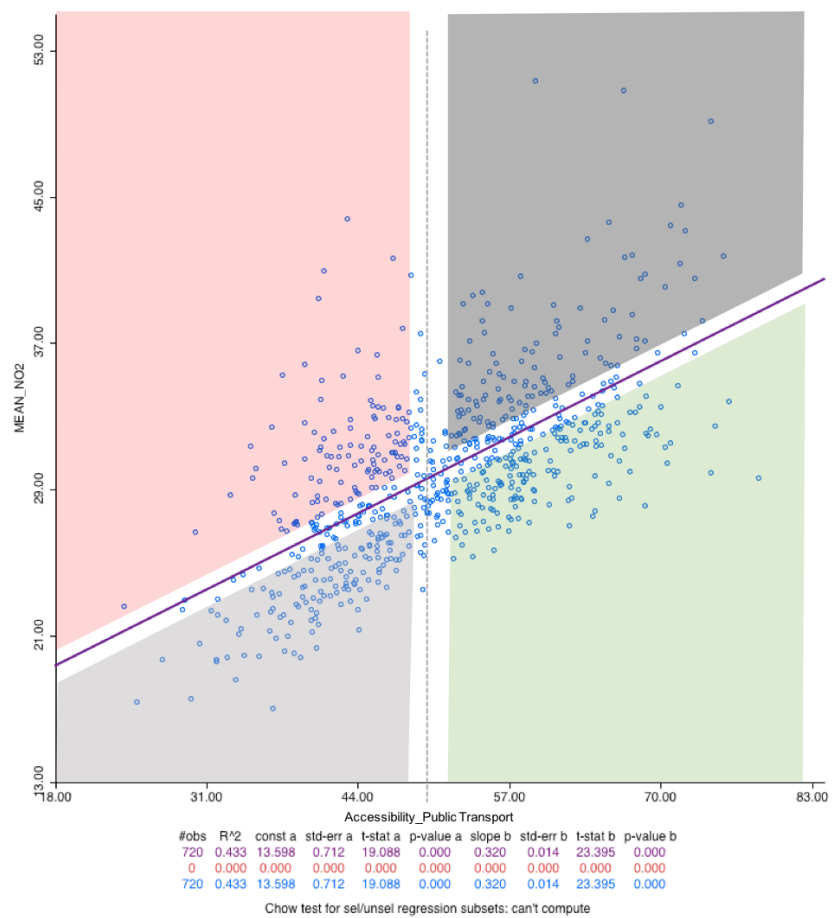

Figure 4 - Public transport accessibility $\& \mathrm{NO}_{2}$ annual mean correlation

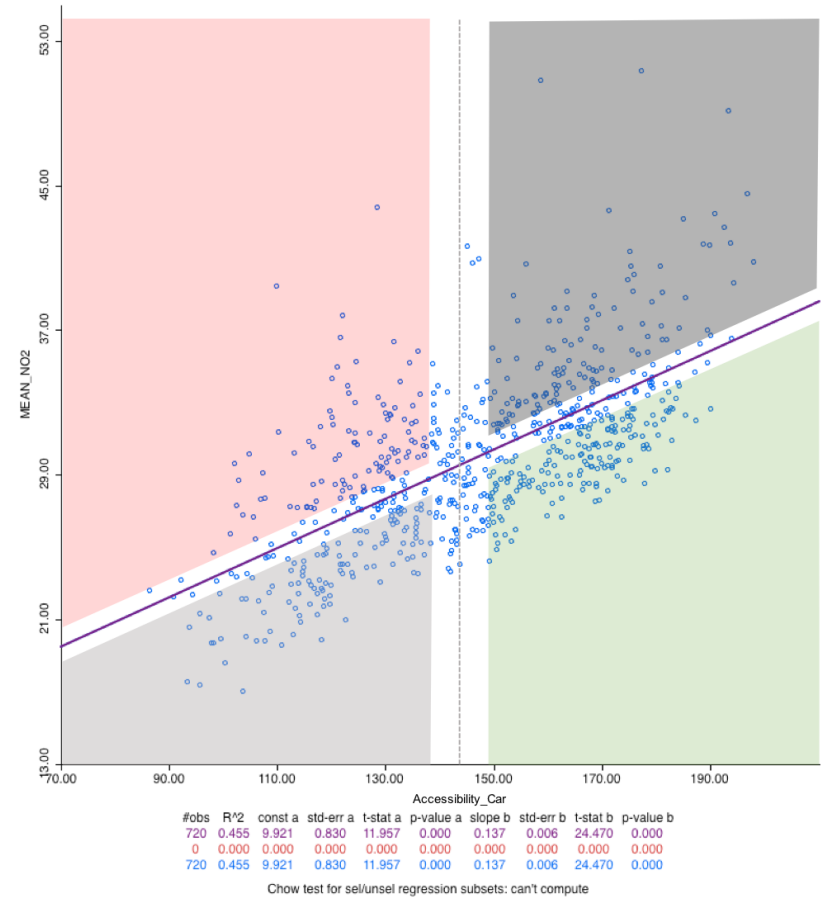

Figure 5 - Car accessibility \& $\mathrm{NO}_{2}$ annual mean correlation 


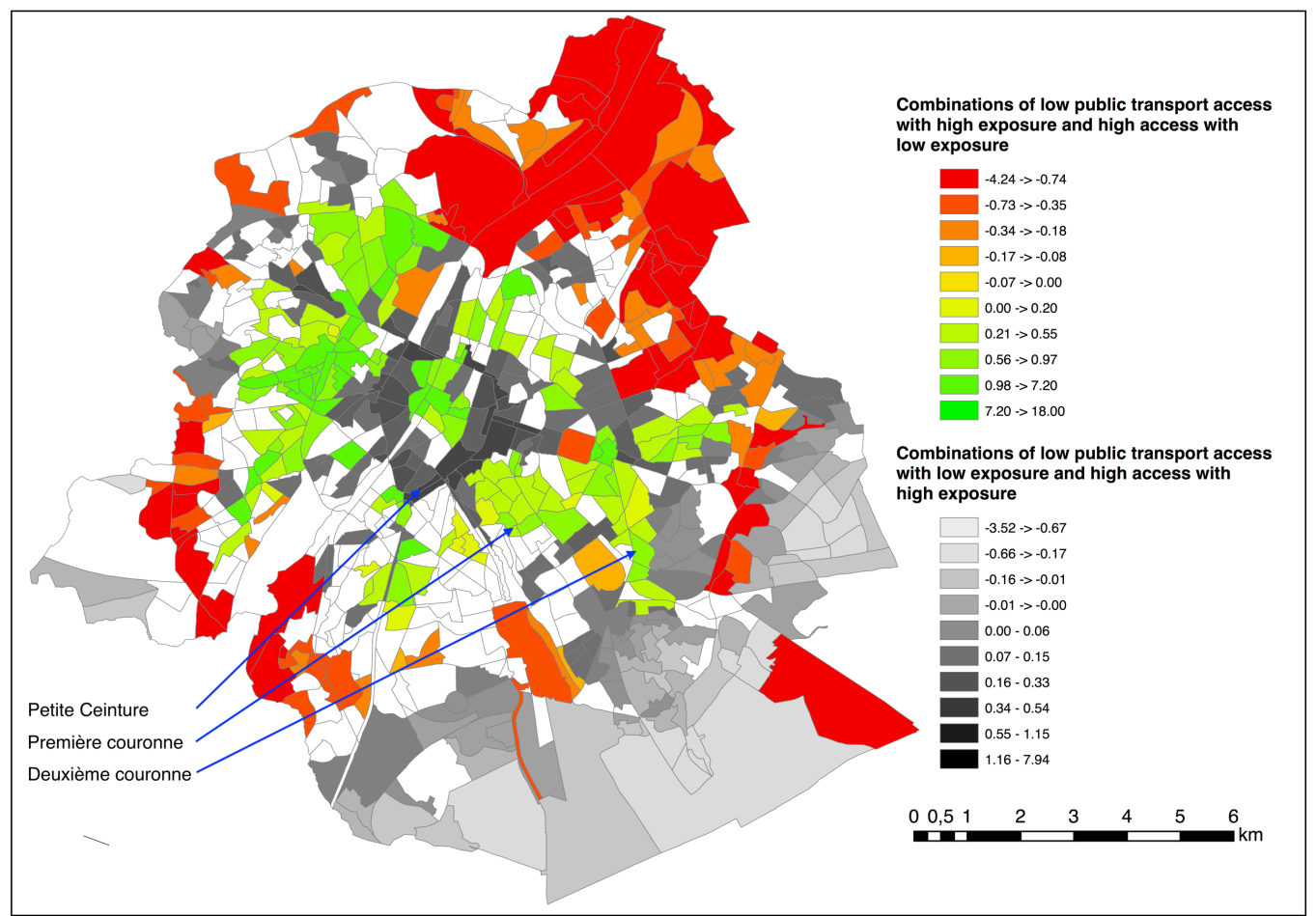

Figure 6 - Agglomeration map (combination of $\mathrm{NO}_{2}$ \& public transport accessibility)

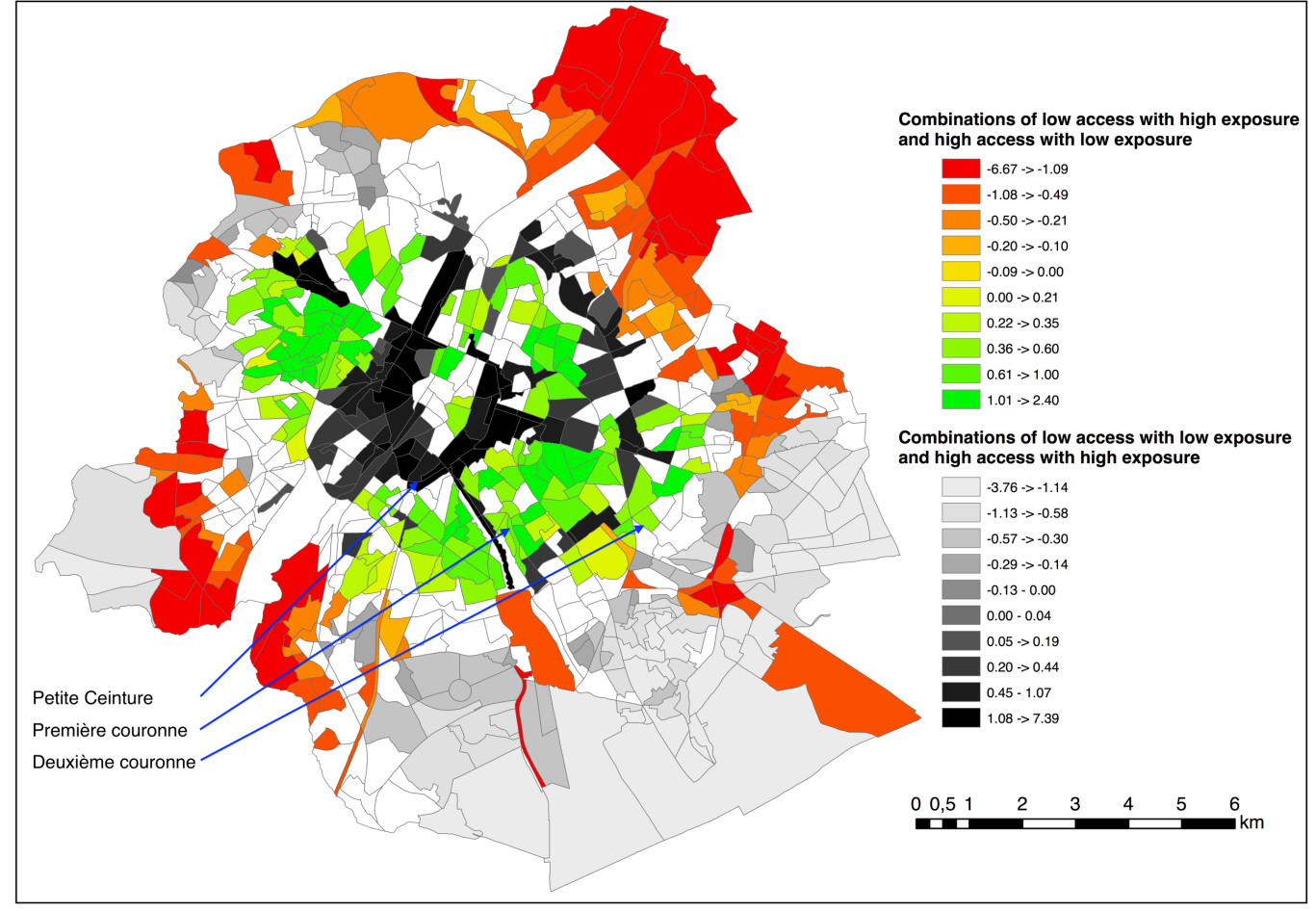

Figure 7 Agglomeration map (combination of $\mathrm{NO}_{2}$ \& car accessibility) 


\section{The geography of urban desirability}

The maps in Figures 6 and 7 are geographical representations of Figures 4 and 5, and show the location of the four different types of neighbourhoods. The two maps look relatively similar, considering that they are based on the same $\mathrm{NO}_{2}$ values and on accessibility indicators that are highly correlated with one another (see Tables 1 and 2 ). Throughout the region, levels of car accessibility are higher than public transport accessibility, generally resulting in higher values both for the agglomeration and the desirability indicators.

Starting from the city centre, we observe a number of census wards which are green in both maps (i.e. characterised by high levels of desirability). While pollution levels here are relatively high, these census wards are extremely centrally located and are very well served by transport infrastructure and in particular by the public transport network (which is why the central green area in Figure 6, is larger than the one in Figure 7).

Next, the neighbourhoods at the border of the 'pentagon' are ultimate expressions of agglomeration dynamics, presenting both high costs (high levels of pollution) and benefits (high levels of accessibility both by car and by public transport). The petite ceinture, i.e. Brussels internal ring-road, has historically been one of the structuring axes of regional mobility both for cars and for public transport, hence the high level of accessibility in both maps. The high traffic along it, however, results also in extreme levels of pollution, which regularly exceed WHO and EU limits. The same situation is observed in some of the traffic arterials that irradiate toward the periphery as well as part of the eastern boulevard, running along the eastern part of the city midway between the petite ceinture and the external ring road.

In the neighbourhoods immediately surrounding the historical city, i.e. in the so-called first belt (première couronne) and part of the second belt (deuxième couronne), we observe what are possibly the most desirable census wards, combining optimal conditions both in terms of accessibility and air quality. While they are still relatively central and densely populated, and thus show high levels of accessibility, they are characterised by average levels of pollution. With the exception of big arterials, traffic volumes are contained and no other major polluting source is located here.

Further away from the city centre, we observe the worse performing census wards, combining high agglomeration costs (higher-than-expected pollution levels) with low benefits (lower-thanaverage accessibility levels). While the decentralised position and the low population density result in low accessibility scores, the presence of high density traffic routes possibly contributes to higher-than expected-pollution levels. In the southern fringe, where large wooded areas are located, we note a situation where the low-accessibility score is offset by the low pollution level. Figure 8 is useful to compare neighbourhoods which are better accessible either by car or by public transport, while visualising their air quality scores. The four maps are displayed on a matrix visualising car accessibility on the horizontal axis (high values on the right column and low values on the left column) and public transport accessibility on the vertical one (high values on the top row and low values on the bottom row). The map on the top-right corner shows the location of census wards with high levels of accessibility both by car and by public transport. The map on the bottom-left corner, conversely, shows the census wards with low levels of accessibility by car and by public transport. Considering the strong correlation between public transport and car accessibility, most census wards appear in these two maps. The other two maps show the location of the outliers, combining high levels of accessibility by public transport and low levels 
of accessibility by car (top-left corner), and the reverse (bottom-right corner).The colour coding indicates the $\mathrm{NO}_{2}$ annual mean concentration.

We observe clear patterns for neighbourhoods that show high accessibility levels both by car and by public transport, which are generally highly polluted, as well as for those neighbourhoods that show low accessibility levels for both modes, which are generally less polluted. This is not the case for the maps showing the location of the outliers, both presenting various degrees of pollution levels. In other words, the map suggests that high levels of public transport accessibility in areas with low levels of car accessibility is not a guarantee for lower levels of air pollution.

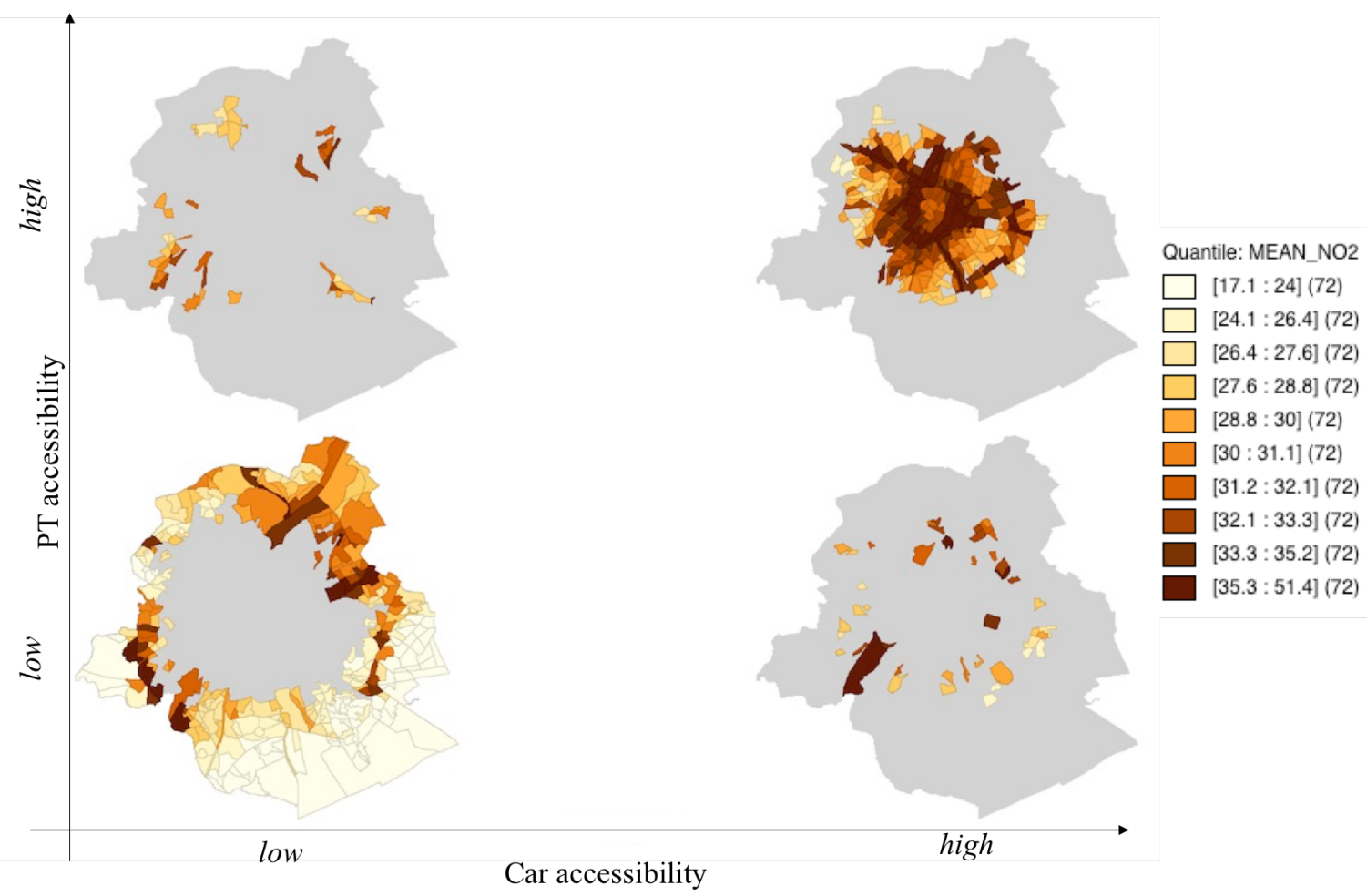

Figure 8 - Location of census wards showing different combinations of public transport and car accessibility, and their pollution level

\section{Uneven geography of benefits and costs}

The section above illustrated how the location of agglomeration and desirability values follows a concentric pattern; going from the city-centre to the suburbs we observe a sequence of circular zones (albeit imperfect), displaying different conditions in terms of the agglomeration trade-off we introduced above. This is a picture which is fundamentally different from the one based on the city's socio-economic characteristics. Different studies show how the BCR socio-economic geography is largely based on the historical industrial axes along the Brussels-Antwerp canal, with underprivileged neighbourhoods concentrating poverty, unemployment, low education, poor health (etc.) located on the north-western part of the region (i.e. on the low lands, on the western bank of the canal), vis-à-vis the wealthier ones on the south-eastern part (Corijn \& Vloeberghs, 2009, p. 226; Deboosere, Eggerickx, Van Hecke, \& Wayens, 2009, p. 9).

Tables 1 and 2 already showed that neither air pollution nor accessibility are significantly correlated with property values. In addition, we also looked at the $10 \%$ most and least desirable 
census wards and at the residents' income, using the median of average income levels to distinguish between richer and poorer census wards. In both cases, the proportion of poorer and richer census wards is quite balanced and possibly favours poorer ones (respectively 56\% poorer and $44 \%$ richer census wards among the ones showing high desirability, and $44 \%$ and $56 \%$ among the ones showing low desirability ${ }^{4}$ ). In this context, we do not observe any correspondence between the distribution of the agglomeration costs and benefits on one hand, and socioeconomic characteristics of the residents on the other. This means that our second hypothesis is not confirmed (\#2 - spatial justice hypothesis). Interestingly, however, other parameters related to our analysis such as the level of satisfaction with neighbourhood cleanliness or self-declared health status, have a somewhat stronger correlation to socio-economic characteristics, their geographic distribution reflecting the north-west/south-east divide along the canal (Institut Bruxellois de Statistique et d'Analyse, 2001a, 2001b).

\section{Discussion and conclusion}

In this article, we explored two characteristics of urban agglomerations, i.e. accessibility and pollution, their relation and their geographic and socio-economic distribution.

Our analysis showed that there is a clear correlation between the two, thereby confirming our first hypothesis (i.e. the agglomeration hypothesis). Well-accessible neighbourhoods are those where much interaction is possible and are therefore the place where many people go - probably by car, considering the modal split in the BCR. The prevalence of high density traffic, in turn, results in higher concentrations of exhaust fumes. These findings provide empirical confirmation to the theoretical reflections on the socio-ecological externalities of urban common living, i.e. that there is a trade-off between positive and negative externalities. It also contributes to the policy literature on sustainable mobility, which does not seem to have provided much evidence in this respect. This trade-off, we should note, is a snapshot of the current condition as far as accessibility and pollution are concerned, and is not an indication of an unavoidable compromise. Stating whether and how this is acceptable and just for a specific neighbourhood or for the city as a whole is a normative claim that lies out of this scope of this article.

The correlation identified does not apply to all neighbourhoods in Brussels. Through the desirability indicator, we have distinguished neighbourhoods that combine high levels of accessibility (i.e. above average) and low levels of pollution (i.e. below expectation). These neighbourhoods are examples representing relatively good conditions and show that it is possible to escape the agglomeration trade-off. In particular, we observe high levels of pollution and accessibility in the urban core and along the main traffic arterials; a belt of 'desirable' neighbourhoods surrounding the historical city, combining high levels of accessibility with belowexpectation levels of pollution; and finally, various clusters of low performing neighbourhoods situated at the BCR's fringes, with the exception of the southern suburbs. The strong correlation between car and public transport accessibility makes it difficult to draw conclusions on the levels of pollution of neighbourhoods that combine different levels of accessibility by car and by public transport.

${ }^{4} 0$ and missing values have been excluded - we focus here on desirability based on car accessibility 
Our analysis, on the other hand, does not provide conclusive results with respect to the relation between the distribution of the agglomeration benefits and costs and the regional socioeconomic stratification (i.e. the spatial justice hypothesis). Correlations between property values and accessibility, and between property values and air pollution are only weakly significant and partially inconsistent (Tables 1 and 2). Indeed, the more 'desirable' neighbourhoods (at least in relation to accessibility and pollution) can be found both in the more expensive and in the cheaper parts of the city. While we do observe flagrant patterns of spatial inequality, this does not immediately reflect the socio-economic structure of the region, as other mechanisms seem to dominate property values.

One mechanism is probably related to the historical path dependency of the urban setting. The current geography of the city's socio-economic stratification, in fact, finds its roots in history, where the north-western neighbourhoods historically had the worst environmental conditions because of industrial activities in the 19th century or the location of the swamps before that. While property values have not adapted to the changing nature and location of air pollution, this might change in the future, considering the increasing concern BCR residents feel for air pollution (European Commission, 2015). Another explanation could be related to the fact that pollution is by and large invisible to the naked eye and is therefore not easily reflected in the demand (or lack thereof) for housing in an area. Further research could explore the possible trade-off between accessibility and other agglomeration costs that are more easily 'sensed' by untrained people (e.g. noise, odours...). Finally, it is also possible that patterns of inequality exist within census wards, especially considering that pollution levels can greatly vary even within building blocks (e.g. depending on the floor, building ventilation, relative proximity to traffic arteries...). Overall, the analysis we propose is relevant for policy making inasmuch as it shows the diversity that exists across neighbourhoods. While, broadly speaking, accessibility and clean air can both be considered as amenities to strive for, the characteristics of a neighbourhood might make it more suitable to prioritise one or the other. Ambitious policies to reduce road capacity, for instance, are possibly suitable for neighbourhoods that are already well accessible but show high levels of pollution, while possibly being too burdensome for others. A similar reasoning could be made in terms of need-oriented provision of urban services, the location of which could be determined on the basis of particular needs or desires for accessibility (e.g. young professionals) or vulnerability to pollution (e.g. elderly people or children).

We also propose a methodology to simultaneously analyse correlated but off-setting externalities of agglomerations. Further research could use a similar methodology to consider different geographical scales or conduct comparative research involving various urban agglomerations. Also, further research can build on our approach and explore other questions of spatial justice. These could focus, for instance, on issues of vulnerability (e.g. problems such as high levels of pollution and low levels of accessibility can have different and potentially unjust implications for different social groups) or on issues of responsibility (e.g. when exposure to pollution does not reflect contribution to it). In addition, we note that accessibility and levels of pollution at the home address provides a limited picture of personal exposure (Dewulf et al., 2016; Dons et al., 2011). In that context, considering individuals' and groups' personal trajectories and capabilities will also contribute to providing relevant insights. 


\section{Acknowledgement}

We would like to thank Kevin Lebrun at Université Saint-Louis - Bruxelles for kindly having provided access to the public transport accessibility indicators for Brussels, which were developed as part of his PhD thesis, defended in 2018.

This research has received funding from the European Union's Urban Europe Joint Programming Initiative under grant agreement no. 854919. The funder has played no role in the research.

The authors declare that they have no significant competing financial, professional or personal interests that might have influenced the performance or presentation of the work described in this manuscript.

\section{Bibliography}

Anselin, L. (1995). Local Indicators of Spatial Association-LISA. Geographical Analysis, 27(2), 93115. https://doi.org/10.1111/j.1538-4632.1995.tb00338.x

Anselin, L., \& Bera, A. (1998). Spatial dependence in linear regression models with an introduction to spatial econometrics. In Handbook of Applied Economic Statistics (Marcel Dekker, pp. 237-289). New York. Retrieved from http://www.econ.uiuc.edu/ hrtdmrt2/Teaching/Spatial_Econometrics_2016/Reference s/Spatial_Dependence_in_Linear_Regression_Models_With_an_Introduction_to_Spatial _Econometrics_281_29.pdf

Anselin, L., \& Lozano-Gracia, N. (2008). Errors in variables and spatial effects in hedonic house price models of ambient air quality. Empirical Economics, 34(1), 5-34. https://doi.org/10.1007/s00181-007-0152-3

Atmosys.eu. (2015). Annual air quality map-service. Retrieved from http://www.atmosys.eu/faces/expertise-high-resolution-modelling.jsp

Barette, P. D. T. (2011). IRIS 2 Mobiliteitsplan Brussels Hoofdstedelijk Gewest. Brussel.

Berger, G., Feindt, P. H., Holden, E., \& Rubik, F. (2014). Sustainable Mobility-Challenges for a Complex Transition. Journal of Environmental Policy \& Planning, 16(3), 303-320. https://doi.org/10.1080/1523908X.2014.954077

Bisht, S. S., Mishra, V., \& Fuloria, S. (2009). Measuring Accessibility for Inclusive Development: A Census Based Index. Social Indicators Research, 98(1), 167-181. https://doi.org/10.1007/s11205-009-9537-3

Boussauw, K., Allaert, G., \& Witlox, F. (2013). Colouring Inside What Lines? Interference of the Urban Growth Boundary and the Political-Administrative Border of Brussels. European Planning Studies, 21(10), 1509-1527. https://doi.org/10.1080/09654313.2012.722952

Brinkman, J. C. (2016). Congestion, agglomeration, and the structure of cities. Journal of Urban Economics, 94(Supplement C), 13-31. https://doi.org/10.1016/j.jue.2016.05.002

Bruxelles Environnement. (2015). 02. Pollution atmosphérique en RBC: constats. Retrieved from http://document.environnement.brussels/opac_css/index.php?lvl=notice_display\&id=7 361 
Bruxelles Environnement. (2016a). 08. Oxydes d'azote (NOx). Retrieved from http://document.environnement.brussels/opac_css/index.php?|vl=notice_display\&id=7 402

Bruxelles Environnement. (2016b, February 18). Etat de l'environnement 2011-2014: Qualité de I'air: concentration en NO2 [Text]. Retrieved July 3, 2017, from http://www.environnement.brussels/etat-de-lenvironnement/rapport-20112014/air/qualite-de-lair-concentration-en-no2

Caschili, S., De Montis, A., \& Trogu, D. (2015). Accessibility and rurality indicators for regional development. Computers, Environment and Urban Systems, 49, 98-114. https://doi.org/10.1016/j.compenvurbsys.2014.05.005

Corijn, E., \& Vloeberghs, E. (2009). Bruxelles! Asp / Vubpress / Upa.

Da Schio, N., de Geus, B., \& Bouland, C. (2017). A brief guide to the air of Brussels. Brussels Centre Observatory Portfolio \#2.

Deboosere, P., Eggerickx, T., Van Hecke, E., \& Wayens, B. (2009). The population of Brussels: a demographic overview. Brussels Studies. La Revue Scientifique Électronique Pour Les Recherches Sur Bruxelles / Het Elektronisch Wetenschappelijk Tijdschrift Voor Onderzoek over Brussel / The e-Journal for Academic Research on Brussels. https://doi.org/10.4000/brussels.891

Deguen, S., \& Zmirou-Navier, D. (2010). Social inequalities resulting from health risks related to ambient air quality-A European review. European Journal of Public Health, 20(1), 27-35. https://doi.org/10.1093/eurpub/ckp220

Dewulf, B., Neutens, T., Lefebvre, W., Seynaeve, G., Vanpoucke, C., Beckx, C., \& Van de Weghe, N. (2016). Dynamic assessment of exposure to air pollution using mobile phone data. International Journal of Health Geographics, 15, 14. https://doi.org/10.1186/s12942-0160042-z

Dons, E., Int Panis, L., Van Poppel, M., Theunis, J., Willems, H., Torfs, R., \& Wets, G. (2011). Impact of time-activity patterns on personal exposure to black carbon. Atmospheric Environment, 45(21), 3594-3602. https://doi.org/10.1016/j.atmosenv.2011.03.064

Duranton, G., \& Puga, D. (2004). Micro-foundations fo Urban Agglomeration Economies. In Handbook of regional and urban economics: cities and geography (Vol. 4, pp. 2063-2117). Amsterdam: Elsevier. Retrieved from http://www.sciencedirect.com/science/article/pii/S1574008004800051

European Commission. (2015). Quality of Life in European Cities. Retrieved from http://ec.europa.eu/regional_policy/sources/docgener/studies/pdf/urban/survey2015_ en.pdf

European Environment Agency. (2017). Air quality in Europe: 2017 report (Publication). Retrieved from https://www.eea.europa.eu/publications/air-quality-in-europe-2017

European Parliament, \& European Council. Directive 2008/50/EC of the European Parliament and of the Council of 21 may 2008 on ambient air quality and cleaner air for Europe, Pub. L. No. 2008/50/EC (2008). Retrieved from http://eur-lex.europa.eu/legalcontent/EN/TXT/PDF/?uri=CELEX:32008L0050\&from=en

Fennell, L. A. $\quad$ (2015). Agglomerama. Retrieved from https://papers.ssrn.com/sol3/papers.cfm?abstract_id=2532270 
Genard, J.-L., Berger, M., \& Vanhellemont, L. (2017). L'architecture Des Débats : Les Imaginaires Mobilisés. Brussels Studies - Brussels Centre Observatory, Portfolio \#1_Cadrages-Kader. Retrieved from http://bco.bsi-brussels.be/13-contributions-originales-en-ligne/

Geurs, K. T., \& van Wee, B. (2004). Accessibility evaluation of land-use and transport strategies: review and research directions. Journal of Transport Geography, 12(2), 127-140. https://doi.org/10.1016/j.jtrangeo.2003.10.005

Glaeser, E. L. (1998). Are cities dying? The Journal of Economic Perspectives, 12(2), 139-160. Retrieved from http://www.jstor.org/stable/2646967

Hajat, A., Hsia, C., \& O’Neill, M. S. (2015). Socioeconomic Disparities and Air Pollution Exposure: a Global Review. Current Environmental Health Reports, 2(4), 440-450. https://doi.org/10.1007/s40572-015-0069-5

Hansen, W. G. (1959). How Accessibility Shapes Land Use. Journal of the American Institute of Planners, 25(2), 73-76. https://doi.org/10.1080/01944365908978307

Harrison, D., \& Rubinfeld, D. L. (1978). Hedonic housing prices and the demand for clean air. Journal of Environmental Economics and Management, 5(1), 81-102. https://doi.org/10.1016/0095-0696(78)90006-2

Institut Bruxellois de Statistique et d'Analyse. (2001a). Part de la population qui déclare ne pas être en bonne santé en Région bruxelloise. Retrieved from https://monitoringdesquartiers.brussels/maps/statistiques-sante-bruxelles/santepercue-region-bruxelloise/part-de-la-population-qui-declare-ne-pas-etre-en-bonnesante/1/2001/

Institut Bruxellois de Statistique et d'Analyse. (2001b). Part des ménages insatisfaits de la propreté aux environs immédiats de leur logement en Région bruxelloise. Retrieved from https://monitoringdesquartiers.brussels/maps/statistiques-environnement-

bruxelles/proprete-region-bruxelloise/part-des-menages-insatisfaits-de-la-propreteaux-environs-immediats-de-leur-logement/1/2001/

Institut Bruxellois de Statistique et d'Analyse. (2015). Densité de population en Région bruxelloise. Retrieved from https://monitoringdesquartiers.brussels/maps/statistiquespopulation-bruxelles/densite-region-bruxelloise/densite-de-population/1/2015/

Janssen, S., Dumont, G., Fierens, F., \& Mensink, C. (2008). Spatial interpolation of air pollution measurements using CORINE land cover data. Atmospheric Environment, 42(20), 48844903. https://doi.org/10.1016/j.atmosenv.2008.02.043

Lebrun, K. (forthcoming). Se déplacer en transport public dans Bruxelles: exploration de l'accessibilité des différents quartiers. Brussels Studies.

Lebrun, K. (2016). L'accessibilité de l'« hypercentre » bruxellois. Premiers résultats pour le transport public. Brussels Centre Observatory Portfolio \#1. Retrieved from http://bco.bsibrussels.be/wp-content/uploads/2016/12/BSI-BCO-P1-Lebrun.pdf

Lefebvre, W., \& Vranckx, S. (Eds.). (2013, May). Validation of the IFDM model for use in urban applications. Atmosys. Retrieved from http://www.atmosys.eu/faces/doc/ATMOSYS_Deliverable_10_IFDM_Model_Validation. pdf

Lucas, K. (Ed.). (2004). Running on empty: transport, social exclusion and environmental justice. Bristol, UK: Policy. 
Lucas, K. (2012). Transport and social exclusion: Where are we now? Transport Policy, 20, 105113. https://doi.org/10.1016/j.tranpol.2012.01.013

Marshall, A. (1890). Principles of Economics: An introductory volume.

Martens, K. (2016). Transport Justice: Designing Fair Transportation Systems. Routledge.

Nelson, J. P. (1978). Residential choice, hedonic prices, and the demand for urban air quality. Journal of Urban Economics, 5(3), 357-369. https://doi.org/10.1016/00941190(78)90016-5

Ridker, R. G., \& Henning, J. A. (1967). The Determinants of Residential Property Values with Special Reference to Air Pollution. The Review of Economics and Statistics, 49(2), 246257. https://doi.org/10.2307/1928231

Schleicher, D. (2009). The City as a Law and Economic Subject. Retrieved from https://papers.ssrn.com/sol3/papers.cfm?abstract_id=1471555

Soja, E. W. (2010). Seeking spatial justice. Minneapolis: University of Minnesota Press.

Srour, I., Kockelman, K., \& Dunn, T. (2002). Accessibility indices: Connection to residential land prices and location choices. Transportation Research Record: Journal of the Transportation Research Board, (1805), 25-34. Retrieved from http://trrjournalonline.trb.org/doi/abs/10.3141/1805-04

Temam, S., Burte, E., Adam, M., Antó, J. M., Basagaña, X., Bousquet, J., ... Jacquemin, B. (2017). Socioeconomic position and outdoor nitrogen dioxide (NO2) exposure in Western Europe: A multi-city analysis. Environment International, 101, 117-124. https://doi.org/10.1016/j.envint.2016.12.026

TOMTOM. (2013). 2013 Multinet BENELUX [Network data set]. [Dataset]. Retrieved from https://www.gim.be/nl/produkten-en-diensten/gis-data/digitale-wegenkaart

UNEP. (2016). ABC for Sustainable Cities. (N. da Schio \& S. Fryxell, Eds.). UNEP \& FIDIC.

Vanhellemont, L. (2016). The Power of Imaginaries in Urban Planning Processes. Università degli Studi di Milano-Bicocca, Milano. Retrieved from https://boa.unimib.it/handle/10281/136378?mode=simple.222

Verbeek, T., \& Boelens, L. (2016). Environmental health in the complex city: a co-evolutionary approach. Journal of Environmental Planning and Management, 59(11), 1913-1932. https://doi.org/10.1080/09640568.2015.1127800

Walker, G. (2012). Environmental Justice: Concepts, Evidence and Politics. Routledge. 